\title{
The Immunogenicity and Anti-Tumor Efficacy of a Rationally Designed EGFR Vaccine
}

\author{
Chao Cheng $^{\mathrm{a}} \quad$ Li Deng $^{\mathrm{b}}$ Rongxiu Li ${ }^{\mathrm{a}}$ \\ aState Key Laboratory of Microbial Metabolism and School of Life Sciences \& Biotechnology, Shanghai \\ Jiao Tong University, Shanghai, 'bShanghai HyCharm Inc. Shanghai, China
}

\section{Key Words}

Cancer vaccine $\cdot$ EGFR $•$ Diphtheria toxin T-domain $•$ CpG

\begin{abstract}
Background/Aims: The abnormally activated EGFR promotes tumor growth, invasion and metastasis. Current therapeutics targeting EGFR have markedly improved the clinical outcome, but they are limited in use due to transient efficacy, frequent administration, high cost and significant toxicity. Methods: We rationally designed a multiepitope immunogen against EGFR, named as DEGFR ${ }^{m}$. The immunogen is composed of an epitope peptide (EGFR ${ }^{265-283}$ ) and the extracellular domain III (EGFR $\left.{ }^{334-505}\right)$ of mouse EGFR. EGFR $265-283$ is grafted onto the translocation domain of diphtheria toxin (DTT), and EGFR ${ }^{334-505}$ is fused to C-terminal of DTT. Next, the immunogenicity and anti-tumor efficacies of DEGFR ${ }^{m}$ vaccine were examined in mouse tumor models. Results: When formulated with Alum and CpG, DEGFR ${ }^{m}$ vaccine elicits Th 1 immune responses and inhibits tumor growth in both prophylactic and therapeutic mouse tumor models. Moreover, the tumor microvasculature is markedly reduced and the tumor infiltration of $\mathrm{CD}^{+} \mathrm{T}$ lymphocytes is greatly enhanced. Conclusions: These data suggest that active immunization with DEGFR ${ }^{m}$ vaccine is a promising strategy for therapy of various EGFR ${ }^{+}$ cancers.

\section{Introduction}

Epidermal growth factor receptor (EGFR) is a single-pass type I membrane protein and a member of receptor tyrosine kinase family. The receptor is composed of an extracellular ligand-binding domain (ECD), a helical transmembrane domain, and a cytoplasmic signaling domain. Upon binding to its ligands such as epidermal growth factor (EGF) and transforming growth factor alpha (TGF- $\alpha$ ), the receptor is dimerized, which activates the receptor tyrosine kinase, and in turn it initiates several signaling cascades such as RAS-RAFMEK-ERK, phosphotidylinositol-3 kinase-Akt, PLCgamma-PKC etc, which contribute to cell proliferation, angiogenesis, and apoptosis resistance [1, 2]. 


\section{Cellular Physiology Cell Physiol Biochem 2018:46:46-56

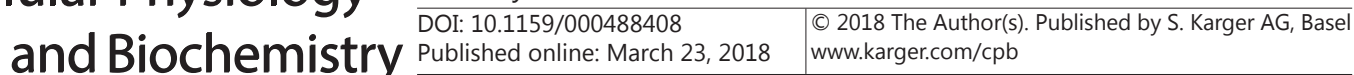 \\ Cheng et al.: The Immunogenicity and Anti-Tumor Efficacy of an EGFR Vaccine}

The abnormal activation of EGFR by aberrant gene amplification or mutation has been associated with tumor progression and poor survival in a number of human cancers including head and neck, colon, lung, ovarian, prostate and pancreatic cancers [3-8]. To date, several anti-EGFR agents have been developed for cancer therapy. The clinically approved therapeutics included small molecular inhibitors such as Iressa and Tarceva, and monoclonal antibodies (mAbs) such as Cetuximab and Panitumumab [2]. However, the clinical application of small molecular inhibitors are limited by their biocompatibility, pharmacokinetics and stability [9], and the monoclonal antibodies are limited in clinical use due to high cost, infusion reactions, toxicity, and emergence of resistance $[10,11]$. It is therefore an urgent need to develop alternative strategies for safer, less toxic, low cost and more efficacious therapeutics.

Active immunization with tumor specific antigens or epitopes formulated with strong adjuvants such as complete Freund's adjuvant (CFA) has been shown therapeutic effect on a number of cancer types [12-14]. The ECD of mouse EGFR is responsible for ligand binding and the receptor dimerization, and is composed of four structural sub-domains, among which the sub-domain II (aa190-334) is responsible for the receptor dimerization, and the sub-domain III (aa335-506) is responsible for the ligand-binding [15]. The sub-domain III possesses two partially overlapping epitopes recognized respectively by anti-tumor monoclonal antibodies Cetuximab and Panitumab. Cetuximab has been clinically approved for treatment of metastatic colorectal cancer, metastatic non-small cell lung cancer and head and neck cancer [2]. Panitumumab has been clinically approved to treat metastatic colon cancer [2] . In this study, we investigated whether active immunization with domains II and III could generate effective immune responses to ablate EGFR-positive tumor cells when immune self-tolerance is breached.

In our previous studies, we show that the translocation domain of diphtheria toxin (DTT) is a safe antigen carrier capable of breaking immune self-tolerance by virtue of its universal help T cell epitopes [16, 17]. Moreover, DTT-based antigen is immunogenic when formulated with Alum, a widely used adjuvant in human vaccination. We and others also show that $\mathrm{CpG}$ enhances antitumor immunity when formulated with cancer vaccine $[18,19]$. Based on these observations, we designed a vaccine formulation comprising a recombinant immunogen against EGFR, named as DEGFR ${ }^{\mathrm{m}}$ vaccine, which was composed of DEGFR ${ }^{\mathrm{m}} \mathrm{CpG}$ and Alum adjuvants. We assessed the immunogenicity and anti-tumor efficacies of DEGFR ${ }^{m}$ vaccine in two mouse tumor models, in which mice are administrated with Lewis lung tumor cells and 4T1 breast tumor cells.

\section{Materials and Methods}

\section{Peptides, cell lines, mice, and adjuvants}

4T1 cells, and Lewis cells were obtained from the American Type Culture Collection (ATCC; Rockville, MD) and cultured in RPMI 1640 with 10\% fetal bovine serum (FBS). Female C57BL/6 and Balb/c mice (6-8 weeks old) were purchased from Chinese Academy of Sciences, Shanghai Experimental Animal Center, and housed on a 12-h light/dark cycle under specific pathogen-free conditions with food and water ad libitum. All animal studies were performed in accordance with the guidelines approved by the Institutional Animal Care and Use Committee of Shanghai Jiao Tong University. Aluminum hydroxide gel (Alum) was purchased from Invitrogen (Carlsbad, CA, USA). A mouse-specific CpG oligo deoxynucleotide (CpG ODN1826, TCCATGACGTTCCTGACGTT) and M-EGFR ${ }^{\mathrm{p}}$ peptide (AMGKLL SLIKGVIVHRLEGVE-GPSL-DTCPPLMLYNPTT YQMDVNPEGKYSFGATCV) were synthesized by GeneScript (Nanjing, China). All chemical reagents were of analytical grade.

The epitope choice and molecular design

We analyzed the structure of complex EGFR-CETUXMAB which was available (PDB code 1YY9). All interatomic distances between residues belonging to the cytokine and residues belonging to the receptor were computed with Discovery Studio 3.5. In order to insert the mouse EGFR epitopes in the DTT domain 


\section{Cellular Physiology Cell Physiol Biochem 2018:46:46-56

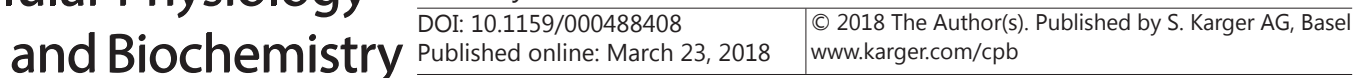 \\ Cheng et al.: The Immunogenicity and Anti-Tumor Efficacy of an EGFR Vaccine}

scaffolds, our lab had found one site that can be used for the most of the foreign epitope for eliciting antibody responses. By employing comparative modeling we have designed our protein in which epitope derived from mouse EGFR ${ }^{262-292}$ epitope, has been inserted into DTT (T domain of diphtheria toxin). Finally, the amino acids 88-94 of DTT was replaced by EGFR ${ }^{265-283}$ (NH2-PLMLYNPTTYQMDVNPEG-COOH) using Discovery studio 3.5. Homology model of fusion protein was built based on the X-ray structure of DTT (PDB entry 1MDT, 2.3Å) using Modeller9V7 [16].

\section{Expression vectors}

The DTT expression vector was described previously [16]. The recombinant DNA fragment encoding DTT T-87-EGFR $^{265-283}$-DTT ${ }^{95-176}$-EGFR ${ }^{334-505}$ was chemically synthesized, cloned into pET-32a after BamHI and Xho I digestion.

\section{DEGFR $^{m}$ expression and purification}

The expression vector was transformed into E. coli Origami B (DE3). A single colony was inoculated into $500 \mathrm{ml}$ of $\mathrm{LB}$ media and cultured on a shaker at $37^{\circ} \mathrm{C}$ until $\mathrm{OD}_{600 \mathrm{~nm}}$ reached to 0.6. Then, IPTG (isopropylthiogalactoside) was added to a final concentration of $0.5 \mathrm{mM}$. The culture was further incubated at $28^{\circ} \mathrm{C}$ for $16 \mathrm{~h}$, after which cells were collected by centrifugation, lysed by ultrasonication, and the protein was purified by Ni-NTA affinity chromatography. The purified protein was digested with PSP (PreScission Protease) in $50 \mathrm{mM}$ Tris- $\mathrm{HCl}, 150 \mathrm{mM} \mathrm{NaCl}, 1 \mathrm{mM}$ EDTA, $\mathrm{pH} 7.0$, at $4^{\circ} \mathrm{C}$ for $12 \mathrm{~h}$, and the cleaved his tag was removed by Ni-NTA affinity column. The flow-through was concentrated and buffer exchanged into PBS buffer. The protein purity was analyzed by SDS-PAGE.

\section{Reverse transcription-polymerase chain reaction (RT-PCR)}

The total RNA and cDNA from tumor cell were got by described preciously. PCR was performed with KOD plus polymerase (Toyobo, Japan). The primers for detecting mEGFR are CGCCGCAAAGTTTGTAATGGCATAGGC and CCGCTAGA CGTGGTTCACGGCCTTGCAGTCTTTC. The condition for PCR reaction is $94^{\circ} \mathrm{C}(2 \mathrm{~min}), 94^{\circ} \mathrm{C}(1$ $\min ), 55^{\circ} \mathrm{C}(30 \mathrm{~s}), 68^{\circ} \mathrm{C}(2 \mathrm{~min}), 30$ cycle, $68^{\circ} \mathrm{C}(10 \mathrm{~min})$.

\section{Mice immunizations}

The vaccine was prepared by mixing $50 \mu \mathrm{g}$ of DEGFR ${ }^{\mathrm{m}}$ and $0.3 \mathrm{mg}$ Alum, with or without $30 \mu \mathrm{g} \mathrm{CpG}$, in 0.1 $\mathrm{ml}$ PBS (phosphate buffer saline) buffer, named as DEGFR ${ }^{\mathrm{m}}+\mathrm{Alum}+\mathrm{CpG}$ and $\mathrm{DEGFR}^{\mathrm{m}}+\mathrm{Alum}$, respectively. Mice were intramuscularly immunized four times at two-week interval. In the control experiments, mice received either PBS or DTT+Alum+CpG. Sera were collected from the mice 7 days after each immunization.

\section{Antibody detection}

Anti-EGFR antibody in mouse sera was detected by ELISA. A microtiter plate was coated with $1 \mu \mathrm{g} / \mathrm{mL}$ mouse EGFR (Sino Biological Inc) in $100 \mu \mathrm{g}$ PBS in each well, and incubated at $4^{\circ} \mathrm{C}$ overnight. The nonspecific

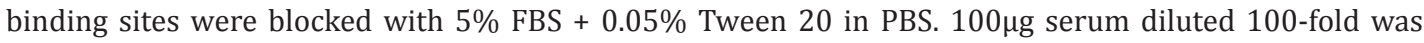
added, and incubated at $37^{\circ} \mathrm{C}$ for $2 \mathrm{~h}$. After the plate was washed three times with PBS, HRP-conjugated goat anti-mouse IgG antibody (200ng/ml, Santa Cruz Biotechnology) was added and incubated at $37^{\circ} \mathrm{C}$ for 1h. Then the plate was washed three times with PBS, and incubated with $100 \mu \mathrm{g}$ TMB solution (Beyotime, cat num P0209) for $15 \mathrm{~min}$, and the reaction was stopped by adding $25 \mu \mathrm{l} /$ well $2 \mathrm{M} \mathrm{H}_{2} \mathrm{SO}_{4}$. The $\mathrm{OD}_{450}$ was measured by a microplate reader (PE EnSpire $\left.{ }^{\mathrm{TM}}\right)$.

Western blot analysis

Ten ng purified DEGFR ${ }^{\mathrm{m}}$ proteins was loaded on $12 \%$ SDS-PAGE, and transferred to PVDF membrane. The membrane was incubated with $5 \%$ milk-PBS at room temperature for $1 \mathrm{~h}$, then $1 \mu \mathrm{g} / \mathrm{ml}$ anti-EGFR antibody (R\&D systems) in $2 \%$ milk-TBS at $4{ }^{\circ} \mathrm{C}$ overnight. After washing three times with PBS, the membrane was incubated with FITC-conjugated goat anti-mouse IgG $(2 \mathrm{ng} / \mathrm{ml})$ at room temperature for $2 \mathrm{~h}$, washed three times with PBS, and analyzed by Odyssey fluorescence imaging system (LICOR, US).

Mouse tumor model experiments

For the 4T1 tumor model experiments, Balb/c mice ( $n=3$ per group) were immunized with indicated vaccine, and on day 32 after the primary immunization, mice received $2 \times 10^{5} 4 \mathrm{~T} 1$ cells. Tumor sizes were 


\section{Cellular Physiology Cell Physiol Biochem 2018:46:46-56

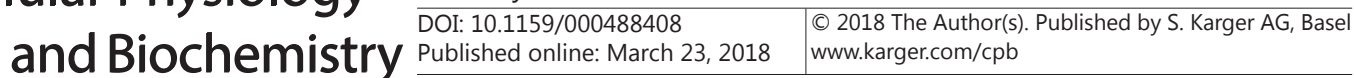 \\ Cheng et al.: The Immunogenicity and Anti-Tumor Efficacy of an EGFR Vaccine}

measured by calipers, and calculated using equation: volume $=\left[(\right.$ length $\left.) \times(\text { width })^{2}\right] / 2$. On day 22 after mice received tumor cells, the mice were sacrificed, and tumors were collected for weight measurement.

For the Lewis tumor model of preventive setting, C57BL/ 6 mice ( $n=5$ per group) were immunized with indicated vaccine, and on day 21 after the primary immunization, mice received $2 \times 10^{5}$ Lewis cells. Tumor sizes were measured as mentioned above. On day 22 after mice received tumor cells, mice were sacrificed, and tumors were collected for weight measurement and immunohistochemistry analysis.

For the Lewis tumor model of therapeutic setting, C57BL/6 mice ( $\mathrm{n}=5$ per group) were immunized with indicated vaccine on day 7 after mice received $2 \times 10^{5}$ Lewis cells. Tumor sizes were measured as mentioned above. On day 23 after mice received tumor cells, the mice were sacrificed, and tumors were collected for weight measurement.

\section{T cell proliferation}

Splenocytes were isolated from C57BL/6 mouse by Ficoll-Paque density gradient centrifugation on day 21 after primary immunization, seeded into a 96-well plate at $1 \times 10^{5}$ cells/well in $100 \mu \mathrm{l}$ of RPMI-1640 $+10 \%$ FBS, and incubated for indicated days at $37^{\circ} \mathrm{C}$ for $4 \mathrm{~h}$. After stimulation with $10 \mu \mathrm{g} / \mathrm{ml}$ mouse EGFR (Sino Biological Inc) for $72 \mathrm{~h}, 10 \mu \mathrm{l} /$ well MTT solution (Beyotime, Jiangsu, China) was added, and incubated at $37^{\circ} \mathrm{C}$ for $4 \mathrm{~h}$, and then $100 \mu \mathrm{l} /$ well dimethylsulfoxide (DMSO) was added. The plates were kept on an orbital shaker for $5 \mathrm{~min}$. The absorbance at $570 \mathrm{~nm}$ was measured by a microplate reader (PE EnSpire ${ }^{\mathrm{TM}}$ ) $[19,20]$.

For $\mathrm{T}$ cell subtype detection, freshly isolated splenocytes were stimulated with mouse EGFR (Sino Biological Inc) for $72 \mathrm{~h}$. After washing 3 times with PBS, cells were stained with anti-CD3-PE、 anti-CD4FITC and anti-CD8-APC antibodies (BD Biosciences, USA) in $1 \mu \mathrm{g} / 10^{6}$ cells in $100 \mu \mathrm{l}$ PBS with $2 \%$ FBS, and analyzed using BD FACSCalibur ${ }^{\mathrm{TM}}$ (Becton Dickinson, USA). The unstimulated cells were used as a negative control. All experiments were repeated 3 times.

\section{Detection of intracellular interferon- $\gamma($ IFN- $\gamma)$}

Intracellular IFN- $\gamma$ was examined as described [19]. Briefly, splenocytes were incubated with brefeldin A (10mM, MultiSciences, China) for 6 hours to block IFN- $\gamma$ secretion. Then the cells were stained with anti-CD3-FITC and anti-CD8-PE antibodies $\left(1 \mu \mathrm{g} / 10^{6}\right.$ cell, eBiosciences) in $100 \mu \mathrm{l} 2 \%$ FBS-PBS. After washing with PBS, cells were fixed with IC fixation buffer (MultiSciences) at room temperature for half an hour, permeabilized with $1 \times$ EB permeabilization buffer, stained with anti-mouse IFN $\gamma$-APC $\left(1 \mu \mathrm{g} / 10^{6}\right.$ cell, eBioscience), and analyzed by FACS Calibur ${ }^{\mathrm{TM}}$ (Becton Dickinson, USA).

\section{Quantitative PCR assay}

Tumor tissue RNA was prepared using TRIzol reagent (Invitrogen). $1 \mu \mathrm{g}$ total RNA was reversetranscribed into cDNA using Maxima First Strand cDNA Synthesis Kit (Fermentas, USA) following manufacturer's instructions. Real time PCR was performed using the SYBR Green kit (Fermentas, USA) following the manufacturer's instructions. Data was analyzed using the 2- ${ }^{\Delta \Delta C T}$ method $[19,21]$. The primer sequences are listed in Table 1.

\section{Immunohistochemistry analysis}

The formalin-fixed, paraffin-embeddedtumor tissues were cut into $4 \mu \mathrm{m}$-slides according to Foy $\mathrm{KC}$ et al. [22]. The slides were blocked with 5\% FBS in PBS at room temperature for $2 \mathrm{~h}$, and incubated at $37^{\circ} \mathrm{C}$ for $2 \mathrm{~h}$ with anti-mouse CD8 and CD3 antibodies. After washing 3 times with PBS, the slides were further incubated with HRP-labeled secondary antibody for $1 \mathrm{~h}$. The amount of bound secondary antibody was visualized with DAB solution (3, 30-diaminobenzidine tetrahy-drochloride) and the slides were counterstained with hematoxylin, and evaluated by Image J software on five representative fields by two investigators.

Table 1. Primers used in qPCR

\begin{tabular}{lc}
\hline Primer & Sequence $5^{\prime}-3^{\prime}$ \\
\hline mGAPDH-F & GCTAGGACTGGATA AGCAGGG \\
mGAPDH-R & AATCCGTTCACACCGACCTT \\
mCD8a-F & TCAGTTCTGTCGTGCC AGTC \\
mCD8a-R & TCACAGGCGAAGTCCAATCC \\
mIL-2R $\alpha-F$ & AACACCACCGATTTCTGGCT \\
mIL-2R $\alpha-R$ & GCTGGCCACTGCTACCTTAT \\
mIFN- $\gamma$ R $\beta-F$ & TCCTCGCCAGACTCGTTTTC \\
mIFN- $\gamma$ R $\beta-R$ & GGGTCATTGCTGGAAGGTGA \\
mEGFR-F & CGCCGCAAAGTTTGTAATGGCATAGGC \\
mEGFR-R & CCGCTAGACGTGGTTCACGGCCTTGCAGTCTTTC \\
\hline
\end{tabular}




\section{Cellular Physiology Cell Physiol Biochem 2018:46:46-56 and Biochemistry Published online: March 23, 2018 \begin{tabular}{l|l} 
DOI: 10.1159/000488408 & $\begin{array}{l}\text { C } 2018 \text { The Author(s). Published by S. Karger AG, Basel } \\
\text { www.karger.com/cpb }\end{array}$
\end{tabular} \\ Cheng et al.: The Immunogenicity and Anti-Tumor Efficacy of an EGFR Vaccine}

Cytotoxicity assay

Lymphocytes (effector cells) were isolated from immunized mouse spleen, co-cultured with Lewis cells (target cells) at the effector to target ratio of 50:1, 20:1, and 10:1, with total cell concentrations adjusted to $2 \times 10^{5} \mathrm{cells} / \mathrm{ml}$ in 96 -well plate. After co-culture for $20 \mathrm{~h}, 10 \mu \mathrm{l}$ MTT solution was added, and the culture was further incubated at $37^{\circ} \mathrm{C}$ for $4 \mathrm{~h}$. Then, $100 \mathrm{ul}$ DMSO was added, and the plate was placed on an orbital shaker for $5 \mathrm{~min}$. The $\mathrm{OD}_{570 \mathrm{~nm}}$ value was measured by a microplate reader mentioned above, and the cell killing activity was calculated using equation: killing ratio $(\%)=[1$ - (co-culture OD value - effector cells alone OD value)/target cell alone OD value] $\times 100 \%$ [22]

\section{Anti-EGFR PAb inhibit EGFR activation}

Lewis cells were cultured in 6-well plates(Costar), and incubated with serum-free medium(DMEM) overnight. Then anti-EGFR antibody purified from DEGFR ${ }^{\mathrm{m}}$ immunized mouse sera was added to the wells to final concentration of $0.2 \mathrm{mg} / \mathrm{ml}$. The cells were incubated at $37^{\circ} \mathrm{C}$, for $2 \mathrm{~h}$. Next, the cells were incubated with mice EGF (100 ng/ml) for 10 min inDMEM media. The cells were lysed in RIPA buffer (PBS, 1\% Nonidet P-40, $0.5 \%$ sodium deoxycholate, and $0.1 \%$ SDS) with $50 \mathrm{mM} \mathrm{NaF}, 1 \mathrm{mM} \mathrm{Na} \mathrm{VO}_{4}, 5 \mathrm{mM}$ EDTA and $1 \mathrm{mM}$ phenylmethylsulphonylfluoride. Cell extracts were loaded to 8\% SDS-PAGE gels and transferred to PVDF membranes. The membrane was incubated with $5 \%$ milk-PBS at room temperature for $1 \mathrm{~h}$, then with antiEGFR antibody in $2 \%$ milk-TBS at $4^{\circ} \mathrm{C}$ overnight. After washing three times with PBS, the membrane was incubated with FITC-conjugated goat anti-mouse IgG $(2 \mathrm{ng} / \mathrm{ml})$ at room temperature for $2 \mathrm{~h}$, washed three times with PBS, and analyzed by Odyssey fluorescence imaging system (LICOR, US) [23,24].

\section{Statistical analyses}

Statistical significance was analyzed by GraphPad Software, and multiple comparisons were performed using one-way ANOVA. *indicates $\mathrm{P}<0.05$, **indicates $\mathrm{P}<0.01$, and ${ }^{* * *}$ indicates $\mathrm{P}<0.001$, and ns indicates no significant difference.

\section{Results}

The rational design of the immunogen DEGFR

Previous studies have shown that DTT can help break immune self-tolerance when an immunogen is fused to its C-terminal [16]. For immunogen specific against mEGFR, both ECD domain II (aa190-334) and domain III (aa335-505) are considered as they are functionally important for the receptor activation. However, Domain II is difficult to be solubly expressed in $E$ coli because of its high cysteine content [24]. Interestingly, Lei Zhu found that a B cell epitope peptide in the $\beta$-hairpin loop (aa 262-292) directly involving in the receptor dimerization could induce high titers of anti-EGFR antibody and anti-tumor effect when formulated with CFA [25]. Therefore, we chose this peptide as one part of the immunogen. In order to mimic the native conformation of the epitope peptide, we grafted the peptide onto the DTT at positions $a^{88-94}$ that has been shown an ideal site for epitope presentation [16]. EGFR ${ }^{265-283}$ is grafted to minimize structural perturbation of the carrier DTT, according to the method of Li Zhang et al. [16]. To achieve higher anti-tumor efficacy of the vaccine, we considered fusion of ECD subdomain III to the C-terminal of DEGFR ${ }^{p}$. The subdomain III contains two partially overlapping epitopes recognized by monoclonal antibody Cetuximab and Panitumumab, respectively. The resulting immunogen named DEGFR ${ }^{\mathrm{m}}$. We examined the immunogenicity of the resulting immunogens in mice, with EGFR ${ }^{265-283}$ fused to C-terminal of DTT (D-EGFR ${ }^{p}$ ) or MVF (M-EGFR ${ }^{p}$ ) as controls (Fig 1). As shown in Fig. 1A, DEGFR ${ }^{p}$ elicits stronger antibody response against mouse EGFR than D-EGFR suggesting that a more stable conformation of the epitope peptide is beneficial to eliciting antibody response. No anti-EGFR antibody response was detectable in M-EGFR ${ }^{\mathrm{p}}$ immunized mice, probably due to adjuvant Alum, which is milder than CFA used in the previous M-EGFR ${ }^{p}$ study [25].

To achieve higher anti-tumor efficacy of the vaccine, we considered fusion of ECD subdomain III to the C-terminal of DEGFR ${ }^{p}$. The subdomain III contains two partially overlapping epitopes recognized by monoclonal antibody Cetuximab and Panitumumab, 


\section{Cellular Physiology Cell Physiol Biochem 2018;46:46-56 and Biochemistry Published \begin{tabular}{l|l} 
DOI: 10.1159/000488408 & $\begin{array}{l}\text { C } 2018 \text { The Author(s). Published by S. Karger AG, Basel } \\
\text { www.karger.com/cpb }\end{array}$
\end{tabular}

Fig. 1. Immunogenicity of purified recombinant immunogens against EGFR. A. Female C57BL/6 mice (6-8 weeks old, $\mathrm{n}=5$ ) were immunized on day 0 , day 14 and day 28 with $50 \mu \mathrm{g}$ indicated immunogen and $0.3 \mathrm{mg}$ Alum. After 3 immunizations, antiEGFR antibody responses were measured by ELISA. DEGFR ${ }^{\text {: }}$ graft the peptide $\left(\mathrm{EGFR}^{265-283}\right)$ onto the DTT at positions aa88-94. D-EGFR ${ }^{\mathrm{p}}$ : the peptide $\left(\mathrm{EGFR}^{265-283}\right)$ fused to C-terminal of DTT; M-EGFR ${ }^{\mathrm{p}}$ : the peptide $\left(\mathrm{EGFR}^{265-283}\right)$ fused to C-terminal of MVP. B. SDS-PAGE analysis of purified DTT and DEGFR $^{\mathrm{m}}$. DEGFR ${ }^{\mathrm{m}}$ : fusion of ECD subdomain III to the C-terminal of DEGFR ${ }^{\mathrm{p}}$. C. Western blot analysis of DEGFR ${ }^{m}$ with EGFR-specific antibody. DTT was used as a control. D. Female C57BL/6 mice (6-8 weeks old, $n=7$ ) were immunized on day 0 , day 14 and day 28 with $50 \mu \mathrm{g}$ indicated immunogen and $0.3 \mathrm{mg}$ Alum. After 3 immunizations, anti-EGFR

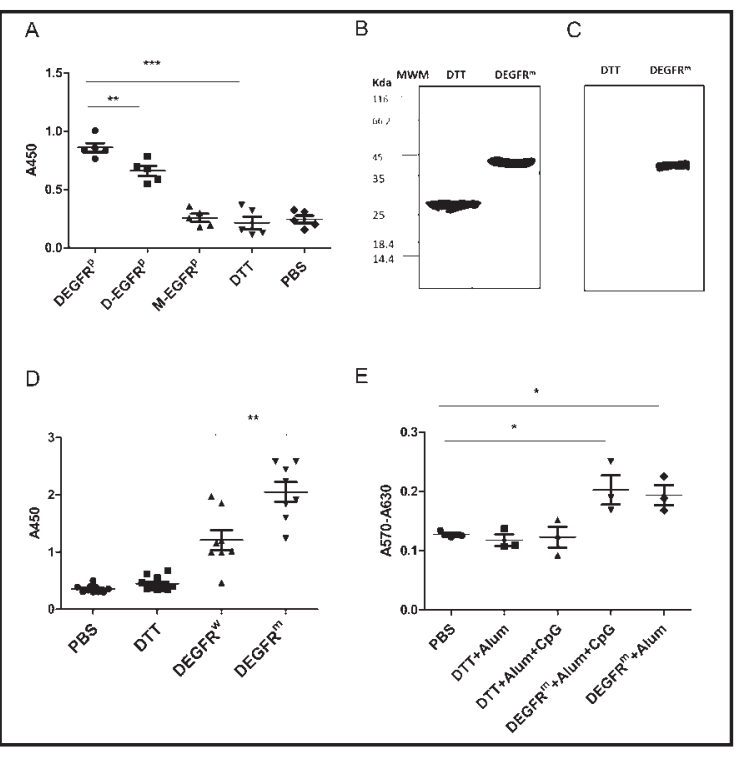
antibody responses were measured by ELISA. DE-

$\mathrm{GFR}^{\mathrm{m}}$ : fusion of ECD subdomain III to the C-terminal of DEGFR ${ }^{\mathrm{p}}$. DEGFR ${ }^{\mathrm{w}}$ : fusion of ECD subdomain III to the C-terminal of D-EGFR ${ }^{p}$. E. Female C57BL/6 mice (6-8 weeks old, $n=3$ ) were immunized on day 0, day 14 and day 28 with $50 \mu \mathrm{g}$ indicated immunogen and $0.3 \mathrm{mg}$ Alum, with or without $30 \mu \mathrm{g} \mathrm{CpG}$. After 3 immunizations, splenocytes were isolated and stimulated with $10 \mu \mathrm{g} / \mathrm{ml}$ mouse EGFR for $72 \mathrm{~h}$. Then the proliferation of the splenocytes was measured by MTT assay.

respectively. The resulting immunogen was named DEGFR ${ }^{\mathrm{m}}$. We found that the recombinant protein DEGFR ${ }^{\mathrm{m}}$ exists in both soluble and insoluble form when expressed in E coli. The soluble fraction was purified to homogeneity as shown in Fig. 1B. Western blot analysis confirmed that DEGFR ${ }^{m}$ is recognized by an EGFR specific antibody (Fig. 1C). The final yield of the purified protein is $0.5 \mathrm{mg} / \mathrm{L}$.

We next examined the anti-tumor immunity of DEGFR ${ }^{\mathrm{m}}$ in mice using DTT and DEGFR ${ }^{\mathrm{w}}$ as control. DEGFR ${ }^{\mathrm{w}}$ is composing of DTT C-terminal fused with EGFR ${ }^{334-505}$, and then fused again with EGFR ${ }^{262-292}$ as C-terminal. Fig. 1D shows that both DEGFR $^{\mathrm{m}}$ and DEGFR ${ }^{\mathrm{w}}$ induced robust anti-EGFR antibody responses with $\mathrm{DEGFR}^{\mathrm{m}}$ treated mice had higher antibody titers.

To examine whether the vaccination elicit cellular memory responses, we in vitro stimulated splenocytes from the immunized mice of various groups with DEGFR $^{\mathrm{m}}$, and examined the cell proliferation by MTT assay. As shown in Fig. 1E, significant cell proliferation was detected in the splenocytes from mice immunized with DEGFR ${ }^{\mathrm{m}}+$ Alum and $\mathrm{DEGFR}^{\mathrm{m}}+$ Alum $+\mathrm{CpG}$, but not in those immunized with DTT+Alum+CpG, DTT+Alum, or PBS.

\section{DEGFR ${ }^{m}$ inhibits tumor growth and neoangiogenesis}

To examine whether the vaccination inhibits tumor growth, we measured the tumor volumes after the immunized mice received the breast cancer 4T1 cells or Lewis lung cancer cells. Fig. 2A shows that, 4T1 tumor grew significantly slower in mice immunized with DEGFR $^{\mathrm{m}}+$ Alum $+\mathrm{CpG}$ while the tumor growth rate was similar among mice immunized with PBS, or DTT +Alum+CpG, or DEGFR ${ }^{\mathrm{m}}+$ Alum. On day 22 after the mice were challenged with the tumor cells, tumor weights were measured. Consistent with the volume measurments, tumor weights in DEGFR ${ }^{\mathrm{m}}+$ Alum $+\mathrm{CpG}$ treated mice were reduced as compared with those in PBS, or DTT +Alum + CpG, or DEGFR ${ }^{\mathrm{m}}+$ Alum.

Fig. $2 \mathrm{~B}$ shows that $\mathrm{DEGFR}{ }^{\mathrm{m}}+$ Alum $+\mathrm{CpG}$ vaccination also inhibits the growth of Lewis lung tumor in mice. Furthermore, tumors from $\mathrm{DEGFR}^{\mathrm{m}}+$ Alum $+\mathrm{CpG}$ treated mice show significantly reduced microvascular density (Fig. 2E-F), suggesting that active immunization with DEGFR ${ }^{\mathrm{m}}$ inhibits neoangiogenesis. 
Fig. 2. Anti-tumor efficacy of DEGFR $^{\mathrm{m}}$ in mouse tumor models. A. Preventive breast cancer model. Balb/c mice ( $\mathrm{n}=3$ per group) were immunized with $50 \mu$ DEGFR $^{\mathrm{m}}$ and $0.3 \mathrm{mg}$ Alum, with or without $30 \mu \mathrm{CpG}$, and on day 32 after the primary immunization, mice received $2 \times$ $10^{5} 4 \mathrm{~T} 1$ cells. Tumor sizes were measured by calipers, and calculated using equation: volume = [(length) $\left.\times(\text { width })^{2}\right] / 2$. On day 22 after mice received tumor cells, the mice were sacrificed, and tumors were collected for weight measurement. a. Immunization schedule. b. 4T1 tumor growth curve. c. tumor weight. B. Preventive lung cancer model. C57BL/ 6 mice ( $n=5$ per group) were immunized with $50 \mu \mathrm{g}$ DEGFR $^{\mathrm{m}}$ and $0.3 \mathrm{mg}$ Alum, with $30 \mu \mathrm{CpG}$, and on day 21 after the primary immunization, mice received $2 \times 10^{5}$ Lewis cells. Tumor sizes were measured as mentioned above. On day 22 after mice received tumor cells, mice were sacrificed, and tu-

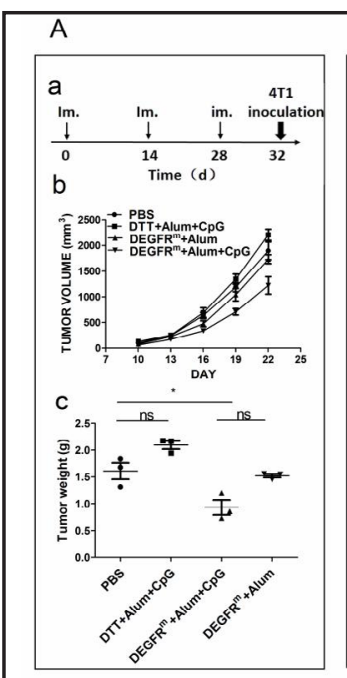

D

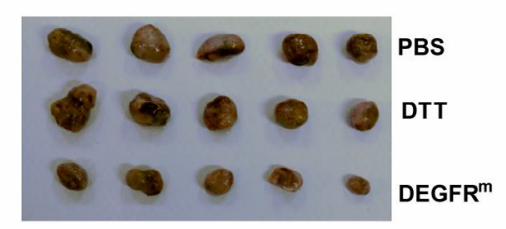

E

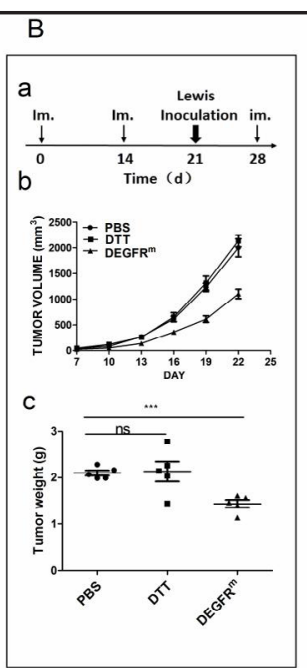

F
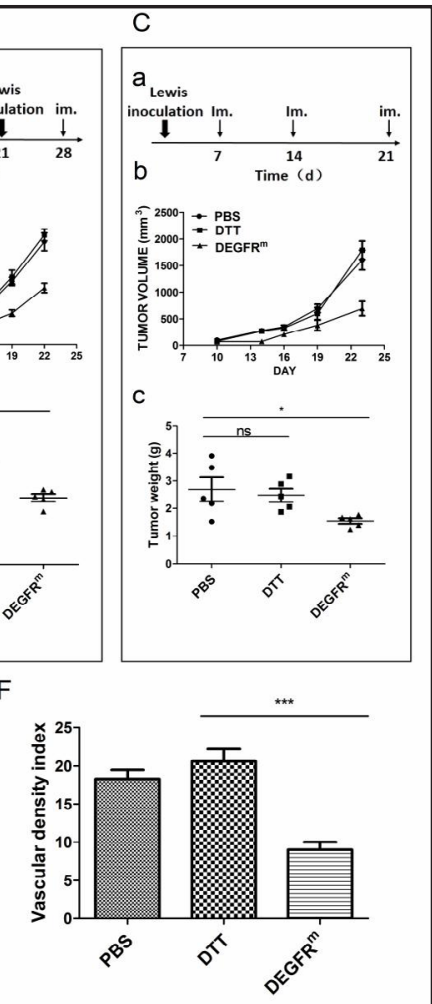

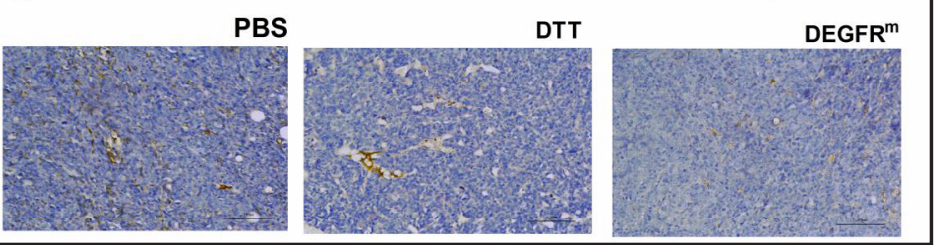
mors were collected for weight measurement and immunohistochemistry analysis. a. Immunization schedule. b. tumor growth curve. c. tumor weight. C. Therapeutic lung cancer model. C57BL/ 6 mice ( $\mathrm{n}=5$ per group) were immunized with with $50 \mu \mathrm{g}$ DEGFR $^{\mathrm{m}}$ and $0.3 \mathrm{mg}$ Alum, with $30 \mu \mathrm{CpG}$, on day 7 after mice received $2 \times 10^{5}$ Lewis cells. Tumor sizes were measured as mentioned above. On day 23 after mice received tumor cells, the mice were sacrificed, and tumors were collected for weight measurement. a. Immunization schedule. b. tumor growth curve. c. tumor weight. D. Tumor samples from mice in B. E. and F. Tumor vasculature analysis from mice in B. The blood vessels were stained with anti-CD31antibody and the vasculature densities were measured using Image J software.

To examine whether the DEGFR ${ }^{\mathrm{m}}+\mathrm{Alum}+\mathrm{CpG}$ vaccination has any therapeutic effect on mouse tumors, we immunized mice 7 days after the mice received Lewis tumor cells, and measured the tumor volumes thereafter. As shown in Fig. 2C, tumors grew significantly slower in mice treated with $\mathrm{DEGFR}^{\mathrm{m}}+$ Alum $+\mathrm{CpG}$ than those in control mice treated with PBS or DTT+Alum+CpG. Consistently, tumor weights on day 23 after the tumor cell challenge were significantly smaller in $\mathrm{DEGFR}^{\mathrm{m}}+$ Alum $+\mathrm{CpG}$ treated mice. These results indicate that DEGFR $^{\mathrm{m}}$ vaccine has a significant therapeutic effect on mice challenged with Lewis tumor cells. Taken together, these results indicate that DEGFR vaccine have a significant tumor inhibition effect.

\section{DEGFR ${ }^{m}$ vaccine induces Th1-type of immunity}

It has been shown a Th1-type of immune response is required for efficient anti-tumor immunity. Therefore, we tested whether DEGFR ${ }^{\mathrm{m}}$ elicits Th1-type of immune response. Fig. 3 A shows that DEGFR ${ }^{\mathrm{m}}$ vaccination induced a strong $\mathrm{mEGFR}$ specific antibody responses. The 


\section{Cellular Physiology Cell Physiol Biochem 2018;46:46-56 and Biochemistry Published / \begin{tabular}{l|l} 
DOI: 10.1159/000488408 & $\begin{array}{l}\text { C } 2018 \text { The Author(s). Published by S. Karger AG, Basel } \\
\text { www.karger.com/cpb }\end{array}$
\end{tabular}

Fig. 3. $\mathrm{DEGFR}^{\mathrm{m}}$ elicits Th1 type of immunity. Female Balb/c mice ( $n=5$ per group) were immunized on day 0 , day 14 and day 28 with $50 \mu \mathrm{g} \mathrm{DEGFR}^{\mathrm{m}}$ and $0.3 \mathrm{mg}$ Alum, with or without CpG. A. After 3 immunizations, anti-EGFR antibodies were measured by ELISA. B. Splenocytes (effector cell) were isolated from immunized mouse spleens, co-cultured with Lewis cells (target cells) at the effector to target ratio of 50:1, 20:1, and 10:1. Cells were co-cultured for $5 \mathrm{~h}$ at $37^{\circ} \mathrm{C} .10 \mu \mathrm{l}$ MTT solution was then added, and the culture was further incubated at $37^{\circ} \mathrm{C}$ for 4h. Then, $100 \mathrm{uL}$ DMSO was added, The OD570nm value was measured by a microplate reader. The cell killing activity was calculated using equation: killing ratio $(\%)=[1$ - $($ co-culture OD value - effector cells alone OD value)/target cell alone OD value $] \times 100 \%$. C. T cell population analysis. The splenocytes from $\mathrm{DEGFR}^{\mathrm{m}}+$ Alum $+\mathrm{CpG}$ group were stained with anti-CD3-PE anti-CD4-FITC and anti-CD8-APC antibodies, and analyzed using BD FACS Calibur ${ }^{\mathrm{TM}}$. D. INF- $\gamma^{+} \mathrm{CD} 8^{+} \mathrm{T}$ cell analysis. Splenocytes from $\mathrm{DEGFR}^{\mathrm{m}}+\mathrm{Alum}+\mathrm{CpG}$ group were incubated with brefeldin A for 6 hours to block IFN- $\gamma$ secretion. Then the cells were stained with anti-CD3-FITC and anti-CD8-PE antibodies. After washing with PBS, cells were fixed with IC fixation buffer, permeabilized with $1 \times$ EB permeabilization buffer, stained with anti-mouse IFN $\gamma$-APC, and analyzed by FACS Calibur TM).

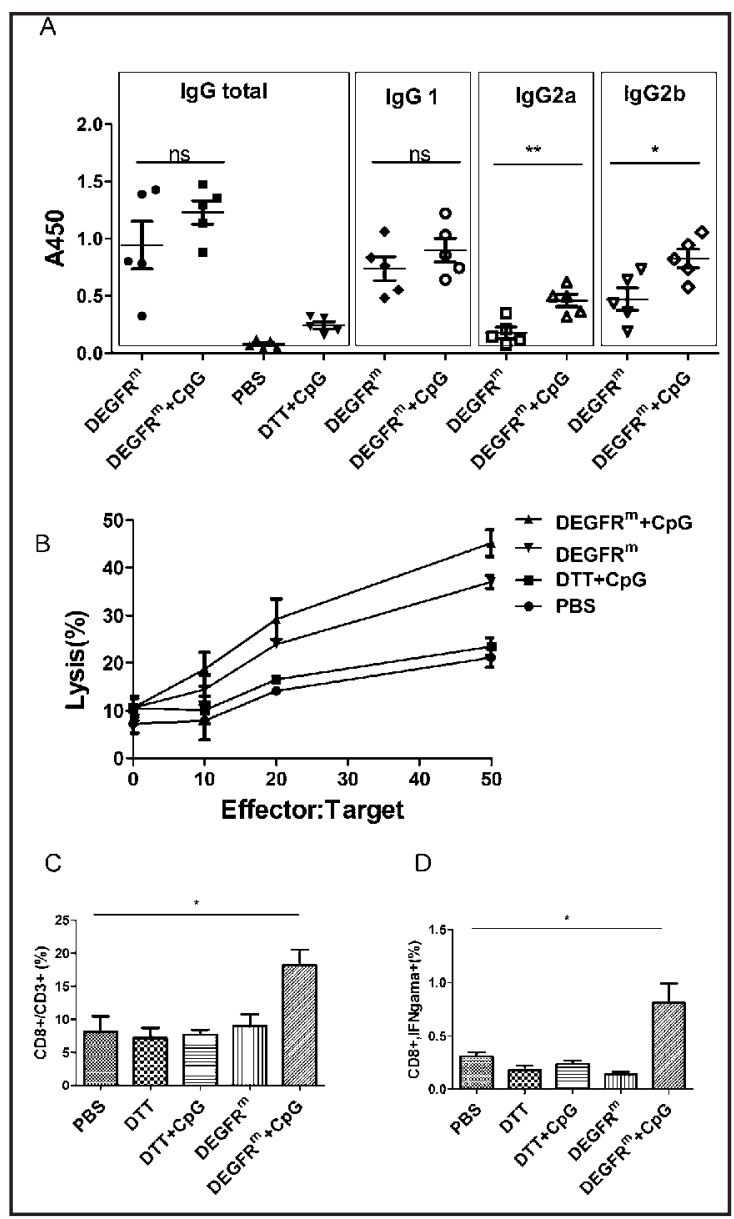

IgG antibody level was higher when the vaccine was formulated with CpG. No anti-mEGFR antibody was detected in DTT or PBS treated mice. Moreover, DEGFR ${ }^{\mathrm{m}}$ induced significant levels of IgG2a and $2 \mathrm{~b}$, and the level increased further in the presence of $\mathrm{CpG}$, suggesting that a Th1-type of immune response is induced, and is consistent with previous reports, CpG help to induce stronger type 1 immunity.

To examine whether the vaccine elicit cytotoxic T-lymphocyte responses, an essential component of Th1 type immunity, Lewis tumor cells were co-cultured with the lymphocytes from mice immunized with DEGFR ${ }^{\mathrm{m}}$ vaccine. As shown in Fig. 3B, the lymphocytes from mice immunized with $\mathrm{DEGFR}^{\mathrm{m}}+$ Alum or $\mathrm{DEGFR}^{\mathrm{m}}+$ Alum + CpG have higher levels of cytotoxicity than mice treated with PBS or DTT +Alum.

We further measured the levels of $\mathrm{CD}^{+} \mathrm{T}$ cells population and $\mathrm{IFN}-\gamma$ secreting effector cells. As shown in Fig. 3C, CD8 ${ }^{+} \mathrm{T}$ cells population was increased by 2.5 fold in $\mathrm{DEGFR}^{\mathrm{m}}+$ Alum $+\mathrm{CpG}$ group as compared to those of the control groups. The IFN- $\gamma$ positive $\mathrm{CD}^{+} \mathrm{T}$ cells were increased by 2 fold. Taken together, our data show that DEGFR ${ }^{\mathrm{m}}+\mathrm{Alum}+\mathrm{CpG}$ elicited Th1 type of immune response.

\section{$D E G F R^{m}$ vaccination enhanced tumor infiltration of $C D 8^{+} T$ cell}

Lymphocyte infiltrating into tumors is a prognostic factor in many cancer treatments [26]. Fig. 4A and B show that the level of tumor infiltrating CD8 ${ }^{+} \mathrm{T}$ cells is significantly increased in mice treated with $\mathrm{DEGFR}^{\mathrm{m}}+\mathrm{Alum}+\mathrm{CpG}$ as compared with other groups of mice. Quantitative reverse transcription-PCR(qRT-PCR) also demonstrated increased expression of CD8a, IFN $-\gamma R \beta$ and IL-2R $\alpha$ in mice vaccinated with the DEGFR ${ }^{\mathrm{m}}+\mathrm{Alum}+\mathrm{CpG}$ as compared to other groups of mice (Fig. 4C-E), which indicate increased CD8 ${ }^{+} \mathrm{T}$ cells and Th1-type of immune cells in tumors of mice treated with DEGFR ${ }^{\mathrm{m}}+$ Alum + CpG. 


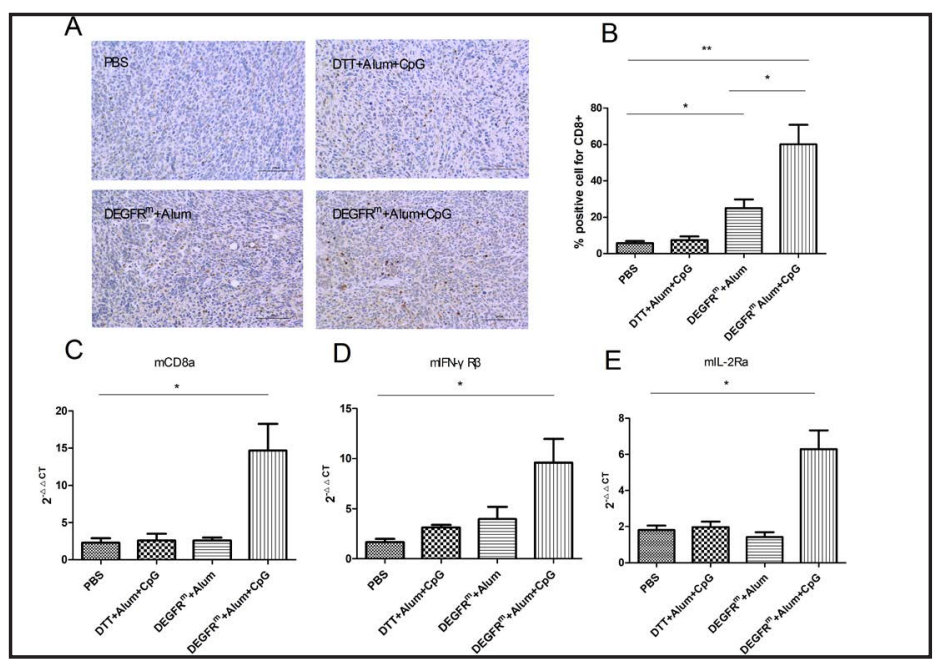

Fig. 4. Tumor infiltration of $\mathrm{CD} 8^{+} \mathrm{T}$ cells and Th1 cytokines in tumor issue. Female C57BL/6 mice (6-8 weeks old, $n=5$ ) were immunized on day 0 , day 14 and day 28 with $50 \mu \mathrm{g} \mathrm{DEGFR}^{\mathrm{m}}$ and $0.3 \mathrm{mg}$ Alum, with CpG. On day 21 after the primary immunization, mice received $2 \times 10^{5}$ Lewis cells. On day 22 after mice received tumor cells, mice were sacrificed, and tumors were collected. A. Immunohistochemical staining of tumor tissue with anti-CD8 antibody. B. CD8 ${ }^{+} \mathrm{T}$ cell density measuremnts by Image J software (National Institutes of Health). $\mathrm{C}$-E. Tumor tissue RNA was extracted and analyzed for expression of IFN $\gamma R \beta$, IL-2R $\alpha$ and CD8a by quantitative reverse transcription-PCR (qRT-PCR).

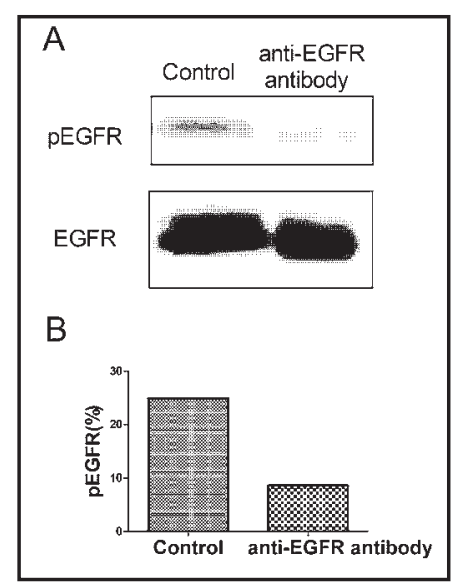

Fig. 5. Anti-EGFR antibody inhibit EGFR phosphorylation. Lewis cells were growth in starvation condition overnight and then incubated with anti-EGFR antibody. EGFR phosphorylation was measured by western blot. Photograph shows EGFR phosphorylation in Lewis cells stimulated with EGF in $0.2 \mathrm{mg} / \mathrm{mL}$ antiEGFR antibody get from DEGFR ${ }^{\mathrm{m}}$ immunized mice.

\section{Anti-EGFR antibody inhibit EGFR activation}

Anti-EGFR antibody can inhibit tumor cells proliferation by blocking EGFR and downstream signaling transduction. Sera from immunized mice were assayed. Lewis cells were incubated with anti-EGFR antibody purified from DEGFR ${ }^{\mathrm{m}}$ immunized mice or unimmunized mice. Anti-EGFR antibody can inhibited EGFR phosphorylation by inhibition of exogenous EGF binding (Fig. 5). But without addition of exogenous EGF, there is no obvious inhibition.

\section{Discussion}

The extracellular domain (ECD) of EGFR has been successfully targeted for the development of inhibitory antibodies, in particular the subdomain III of ECD [27, 28]. In this study, we designed a multi-eptipope vaccine against two separate ECD regions of mouse EGFR. The results showed that the vaccine enhanced Th1 type of immune responses with high titers of IgG and a significant level of cytotoxic T lymphocytes. In addition, it could elicit humoral and cellular immune response reduces tumors growth against two separate ECD regions of not only in prophylactic setting but also in therapeutic setting.

It is well appreciated that a Th1 type of immune response is required for anti-cancer immunity. As a clinically approved adjuvant for human vaccine, alum is rarely used in formulation of human cancer vaccine because it facilitates Th2 type of immune response. Interestingly, work from $\mathrm{Lu}$ et al. show that in presence of $\mathrm{CpG}$, alum formulated cancer vaccine is effective in eliciting Th1 type of immune responses [19]. Consistent with this report, we showed that $\mathrm{CpG}$ and Alum formulated DEGFR ${ }^{\mathrm{m}}$ could elicit Th1 type of immune response and anti-tumor effect in mouse tumor models. This more balanced immune response is assumed to be more beneficial for eliciting systemic anti-tumor immune response. 


\section{Cellular Physiology Cell Physiol Biochem 2018:46:46-56 \begin{tabular}{l|l} 
and Biochemistry Published online: March 23, 2018 & $\begin{array}{l}\text { (c) } 2018 \text { The Author(s). Published by S. Karger AG, Basel } \\
\text { www.karger.com/cpb }\end{array}$
\end{tabular}

DTT has been shown as a safe vaccine carrier and epitope peptide scaffold, and can help to break immune self-tolerance [16]. When a TNF epitope grafted onto DTT, it maintained in a native like conformation. Our data show an EGFR epitope grafted onto DTT at the similar position also induces antibody response against native EGFR, which demonstrates again that DTT is a safe and effective carrier for cancer vaccine design for targeting self-molecules in particular.

Previous studies on EGFR vaccines, eukaryo expressing system were employed to generate recombinant protein immunogen because of their large molecular size and cysteine rich property that exclude the soluble expression in E coli $[24,29,30]$. DEGFR ${ }^{\mathrm{m}}$ circumvents the eukaryotic expression system which substantially reduces the manufacture cost. Therefore, a low cost vaccine is manufactory feasible with our design strategy. By including CpG in our vaccine formulation, Alum-induced Th2 type of immune response is suppressed and Th1-type of immune response is enhanced. This more balanced immune response is assumed to be more beneficial for eliciting systemic anti-tumor immune response.

\section{Conclusion}

Data from this study demonstrate that administration of vaccine composed of DEGFR ${ }^{\mathrm{m}}$, CpG and alum could generate both B cell and T cell responses associated with its antitumor activity in mice. Our design strategy warrants to investigate the clinical benefits and therapeutic potential against EGFR over-expression tumors.

\section{Acknowledgements}

This work was supported by the National key research and development program of China(2017YFC0909002), and the National Science \& Technology Major Projects of China (Major Infectious Diseases 2017ZX10201301-003-004)

\section{Disclosure Statement}

The authors indicate no potential conflicts of interest.

\section{References}

1 Sobani ZA, Sawant A, Jafri M, Correa AK, Sahin IH: Oncogenic fingerprint of epidermal growth factor receptor pathway and emerging epidermal growth factor receptor blockade resistance in colorectal cancer. World J Clin Oncol 2016;7:340-351.

-2 Padfield E, Ellis HP, Kurian KM: Current Therapeutic Advances Targeting EGFR and EGFRvIII in Glioblastoma. Front Oncol 2015;5:5.

3 Dassonville O, Formento JL, Francoual M, Ramaioli A, Santini J, Schneider M, Demard F, Milano G: Expression of epidermal growth factor receptor and survival in upper aerodigestive tract cancer. J Clin Oncol 1993;11:1873-1878.

4 Lockhart AC, Berlin JD: The epidermal growth factor receptor as a target for colorectal cancer therapy. Semin Oncol 2005;32:52-60.

5 Hendler FJ, Ozanne BW: Human squamous cell lung cancers express increased epidermal growth factor receptors. J Clin Invest 1984;74:647-651.

6 Gullick WJ, Marsden JJ, Whittle N, Ward B, Bobrow L, Waterfield MD: Expression of epidermal growth factor receptors on human cervical, ovarian, and vulval carcinomas. Cancer Res 1986;46:285-292.

-7 Zhau HY, Chang SM, Chen BQ Wang Y, Zhang H, Kao C, Sang QA, Pathak SJ, Chung LW: Androgen-repressed phenotype in human prostate cancer. Proc Natl Acad Sci U S A 1996;93:15152-15157.

-8 Tan X, Egami H, Ishikawa S, Nakagawa M, Ishiko T, Kamohara H, Hirota M, Ogawa M: Relationship between activation of epidermal growth factor receptor and cell dissociation in pancreatic cancer. Int J Oncol 2004;25:1303-1309. 


\section{Cellular Physiology Cell Physiol Biochem 2018:46:46-56 \begin{tabular}{l|l|l|l} 
DOI: 10.1159/000488408 2018 The Author(s). Published by S. Karger AG, Basel \\
\hline
\end{tabular} and Biochemistry

9 Jensen KD, Nori A, Tijerina M, Kopeckova P, Kopecek J: Cytoplasmic delivery and nuclear targeting of synthetic macromolecules. J Control Release 2003;87:89-105.

10 Waldmann TA: Immunotherapy: past, present and future. Nat Med 2003;9:269-277.

$\checkmark 11$ Grothey A: Recognizing and managing toxicities of molecular targeted therapies for colorectal cancer. Oncology (Williston Park) 2006;20:21-28.

-12 Sasada T, Azuma K, Ohtake J, Fujimoto Y: Immune Responses to Epidermal Growth Factor Receptor (EGFR) and Their Application for Cancer Treatment. Front Pharmacol 2016;7:405.

-13 Ramirez BS, Alpizar YA, Fernandez DR, Hidalgo GG, Capote AR, Rodriguez RP, Fernandez LE: Anti-EGFR activation, anti-proliferative and pro-apoptotic effects of polyclonal antibodies induced by EGFR-based cancer vaccine. Vaccine 2008;26:4918-4926.

14 Asadi-Ghalehni M, Ghaemmaghami M, Klimka A, Javanmardi M, Navari M, Rasaee MJ: Cancer immunotherapy by a recombinant phage vaccine displaying EGFR mimotope: an in vivo study. Immunopharmacol Immunotoxicol 2015;37:274-279.

15 Nedergaard MK, Hedegaard CJ, Poulsen HS: Targeting the epidermal growth factor receptor in solid tumor malignancies. BioDrugs 2012;26:83-99.

-16 Zhang L, Wang J, Xu A, Zhong C, Lu W, Deng L, Li R: A Rationally Designed TNF- $\alpha$ Epitope-Scaffold Immunogen Induces Sustained Antibody Response and Alleviates Collagen-Induced Arthritis in Mice. Plos One 2016;11:e0163080.

17 Collison J: Rheumatoid arthritis: Paving the way for TNF vaccines. Nat Rev Rheumatol 2016; 12:692.

18 Khong H, Overwijk WW: Adjuvants for peptide-based cancer vaccines. J Immunother Cancer 2016;4:56.

19 Lu W, Qiu L, Yan Z, Lin Z, Cao M, Hu C, Wang Z, Wang J, Yu Y, Cheng X: Cytotoxic T cell responses are enhanced by antigen design involving the presentation of MUC1 peptide on cholera toxin B subunit. Oncotarget 2015;6:34537.

-20 Sladowski D, Steer SJ, Clothier RH, Balls M: An improved MTT assay. J Immunol Methods 1993;157:203207.

-21 Wehland M, Ma X, Braun M, Hauslage J, Hemmersbach R, Bauer J, Grosse J, Infanger M, Grimm D:The impact of altered gravity and vibration on endothelial cells during a parabolic flight. Cell Physiol Biochem 2013;31:432-451.

-22 Foy KC, Wygle RM, Miller MJ, Overholser JP, Bekaii-Saab T, Kaumaya PT: Peptide vaccines and peptidomimetics of EGFR (HER-1) ligand binding domain inhibit cancer cell growth in vitro and in vivo. J Immunol 2013;191:217-227.

-23 Bentz GL and Yurochko AD:Human CMV infection of endothelial cells induces an angiogenic response through viral binding to EGF receptor and $\beta 1$ and $\beta 3$ integrins. Proc Nat Acad Sci 2008;105:5531-5536.

-24 Ramírez BS, Alpízar YA, Fernández DRH, Hidalgo GG, Capote AR, Rodríguez RP, Fernández LE: Anti-EGFR activation, anti-proliferative and pro-apoptotic effects of polyclonal antibodies induced by EGFR-based cancer vaccine. Vaccine 2008;26:4918-4926.

25 Zhu L, Zhao L, Wu M, Chen Z, Li H: B-cell epitope peptide vaccination targeting dimer interface of epidermal growth factor receptor (EGFR). Immunol Lett 2013;153:33-40.

-26 Wilmott JS, Long GV, Howle JR, Haydu LE, Sharma RN, Thompson JF, Kefford RF, Hersey P, Scolyer RA: Selective BRAF inhibitors induce marked T-cell infiltration into human metastatic melanoma. Clin Cancer Res 2012;18:1386-1394.

27 Li S, Schmitz KR, Jeffrey PD, Wiltzius JJ, Kussie P, Ferguson KM: Structural basis for inhibition of the epidermal growth factor receptor by cetuximab. Cancer cell 2005;7:301-311.

28 Bardelli A, Siena S: Molecular mechanisms of resistance to cetuximab and panitumumab in colorectal cancer. J Clin Oncol 2010;28:1254-1261.

-29 Ramírez BS, Pestana ES, Hidalgo GG, García TH, Rodríguez RP, Ullrich A, Férnandez LE: Active antimetastatic immunotherapy in Lewis lung carcinoma with self EGFR extracellular domain protein in VSSP adjuvant. Int J Cancer 2006;119:2190-2199.

-30 Alpízar YA, Ramírez BS, Fernández DRH, Capote AR, Hidalgo GG, Rodríguez RP, Molina LEF: HER1-ECD vaccination dispenses with emulsification to elicit HER1-specific anti-proliferative effects. Hum Vaccin 2009;5:158-165. 